\title{
Changes in Tomato Metabolism by Applying 1,8-Cineole
}

Luis A González, Fernando Torres, Wiston Quiñones and Fernando Echeverri*

Organic Chemistry Natural Products Group, Institute of Chemistry, Faculty of Natural and Exact Sciences, University of Antioquia, Medellín-Colombia

\begin{abstract}
Exposure of unripe tomato fruits to 1,8-cineole vapors modifies several biochemical processes involving flavonoids and lycopene levels; respect to normal ripening fruit, flavonoid concentration is hardly modified whereas lycopene production was delayed after $120 \mathrm{~h}$ of exposure. On the other hand, a ripening deferred is observed in fruits treated with this essential oil. Additionally, biotransformation of 1,8-cineole to 2 -hydroxy derivative is detected.
\end{abstract}

Keywords: Essential oil; Tomato; Ripening; Lycopene; Flavonoids; Biotransformation

\section{Introduction}

Up to $20 \%$ of a crop is lost due to microorganisms and another $10 \%$ in postharvest stage [1]. The application of synthetic chemicals is a useful tool to protect crops and has also allowed an increase of productivity, but dangerous economic and toxicological levels either to the farmer or the environment have been reached. In this regard, natural products and especially essential oils have been deeply studied as pesticides to control plant pathogens, specifically bacteria and fungi $[2,3]$, as well as food preservatives [4]. Despite the difficulties when applying them in the fields due to their high volatility, some of them are commercially available [5].

Eucalyptus oil is well recognized as pesticide with a wide range of uses in agriculture [6]. In search of other substances with similar action, we want to analyze the effects of 1,8-cineole, the main component of eucalyptus oil, over Botrytis cynerea; however, we observed some metabolic modifications in tomatoes as described below. In this study, we report how the application of cineole vapors modify some metabolic parameters of unripe tomato fruits as well as the ripening patterns; we also found that tomato cells are able to bio transform rather quickly and efficiently 1,8-cineole into its 2 -hydroxy-derivative.

\section{Materials and Methods}

\section{General experimental procedures}

Column chromatography was performed using silica gel 60 (200-300 mesh, Merck, Darmstadt, Germany) and Sephadex LH20 (Sigma, St Louis, Mo). For thin layer chromatography, silica gel $60 \mathrm{~F}_{254}$-impregnated aluminum sheets $(0.25 \mathrm{~mm}$, Merck, Darmstadt, Germany) were used. Compounds were detected under UV light (254, $360 \mathrm{~nm})$ after spraying with vanillin $\left(3 \%\right.$ in $\left.\mathrm{H}_{2} \mathrm{SO}_{4}\right)$ and heating at $110^{\circ} \mathrm{C}$.

${ }^{1} \mathrm{H},{ }^{13} \mathrm{C}$ and $2 \mathrm{D}$ NMR spectra of the isolated compounds were recorded on a Bruker DRX 300 spectrometer (Bruker Bio-Spin GmbH, Rheinstetten, Germany) operating at $300 \mathrm{MHz}$ for ${ }^{1} \mathrm{H}$ and $75 \mathrm{MHz}$ for ${ }^{13} \mathrm{C} \mathrm{NMR}$, using $\mathrm{CDCl}_{3}$ (Sigma, St Louis, Mo, USA) as the solvent, and TMS as an internal standard.

\section{Tomato fruits}

Organic tomatoes (Solanum lycopersicum) var. Chonto were obtained directly from a farmer located in El Retiro, Antioquia (Colombia). All fruits were selected unripe, woundless and weighting $110-115 \mathrm{~g}$. The cleaning and disinfection process was carried out with distillated water and then immersed in sodium hypochlorite $2 \%$ for 5 minutes; finally, fruits were rinsed again with distillated water.

\section{Treatment of tomatoes with 1,8-cineole vapors}

The treatment of tomatoes with 1,8-cineole was carried out in transparent boxes $35 \times 19 \times 12 \mathrm{~cm}$ previously sterilized, each box containing 8 green tomatoes (approx. $1 \mathrm{~kg}$ ), randomly selected. On a Petri dish placed at the bottom, $300 \mathrm{~L}$ of pure 1,8-cineole were added and then the box was gently closed. Tomatoes were kept at $25^{\circ} \mathrm{C}, 95 \%$ of relative humidity, for 120 hours, using a 12 hour photoperiod. Assays were made by triplicate, with a control group of untreated cineole tomatoes.

\section{Extraction}

Peeled tomato exocarp (15.6 kg) from approximately $100 \mathrm{~kg}$ of tomatoes treated with 1,8-cineole for $120 \mathrm{~h}$ were milled with $25.0 \mathrm{~L}$ of methanol, which after evaporation under vacuum yielded $600 \mathrm{~g}$ of extract. Then, $1.0 \mathrm{~L}$ of water was added and re-extracted with ethyl acetate $(5 \times 250 \mathrm{~mL})$. The organic phase was evaporated until dryness producing $250 \mathrm{~g}$ of extract; this was separated in a Sephadex LH-20 column chromatograph, eluting with hexane/dichloromethane/ methanol $(2: 1: 1)$. The fraction 25 showed in TLC a mixture of compounds, including a compound with $\mathrm{Rf}=0.41$ in hexane/ethyl acetate $2: 1$, that revealed as a red spot. This compound was absent in the extract of exocarp of untreated 1,8-cineole tomatoes and was purified by preparative tlc in Silica gel $60 \mathrm{~F}_{254}$ in the solvents mixture previously described. Thus, $8 \mathrm{mg}$ of a crystalline solid were recovered.

Similarly, flesh from 1,8-cineole treated and untreated tomatoes was submitted to similar extraction process and analyzed through HPLC and TLC.

\section{HPLC analysis}

*Corresponding authors: Fernando Echeverri, Organic Chemistry Natural Products Group, Institute of Chemistry, Faculty of Natural and Exact Sciences, University of Antioquia, Medellín-Colombia, Tel: +5742196595 ; E-mail: feche@une.net.co

Received September 07, 2015; Accepted October 05, 2015; Published October 12, 2015

Citation: González LA, Torres F, Quiñones W, Echeverri F (2015) Changes in Tomato Metabolism by Applying 1,8-Cineole. J Microb Biochem Technol 7: 323326. doi:10.4172/1948-5948.1000233

Copyright: (c) 2015 González LA, et al. This is an open-access article distributed under the terms of the Creative Commons Attribution License, which permits unrestricted use, distribution, and reproduction in any medium, provided the original author and source are credited. 
1,8-cineole was obtained from Sigma (St. Louis, Missouri USA); HPLC analyses was performed on a Gilson chromatograph equipped with a Gilson model 170 diode array detector, using a Phenomenex Security Guard cartridge C18 $(4.0 \times 3.0 \mathrm{~mm})$ followed by a Waters Spherisorb S5 ODS2 C18 reverse-phase column (4.6 mm i.d x 150 $\mathrm{mm})$. The compounds were eluted at a flow rate of $1 \mathrm{~mL} / \mathrm{min}$ with the solvents $\mathrm{A}=0.5 \%$ acetic acid (Merck, Darmstadt, Germany) in water, and $\mathrm{B}=$ acetonitrile (Merck, Darmstadt, Germany), as follows: $2 \mathrm{~min}$, $1-3 \%$ B; 2-15 min, 3-20\% B; $15-26$ min, 20-35\%; 26-35 min, 35-100\% B; 35-40 min, $100-1 \% \mathrm{~B}$, and subsequently by holding for $8 \mathrm{~min}$ to reequilibrate the column, for the next injection. Injection volume was $20 \mu \mathrm{l}$.

Absorption spectra for the main peaks were recorded at 280, 320 and $370 \mathrm{~nm}$. Peaks of rutin and lycopene in the HPLC chromatograms of the extracts were identified both by retention time and absorption spectrum against those of pure standards, in addition to mass spectrometry.

Initially rutin and lycopene were measured in green untreated 1,8-cineole tomatoes (time 0 ) and after 120 hours; similarly, these compound were also determined in tomatoes treated with 1,8-cineole after 120 hours of exposure. Quantification of rutin was carried out in the HPLC system at $370 \mathrm{~nm}$ using a standard calibration curve by plotting area under curve vs. compound concentration at 3.0, 5.0, 10.0, 15.0 and $20.0 \mathrm{mg} / \mathrm{L}$ in methanol. A straight standard curve was obtained by linear regression using the equation $y=a x+b$, in which $x$ is the concentration of rutin in $\mathrm{mg} / \mathrm{L}$ and $y$ is the detection response ( $y=1048835,955 x-1102021,448), \mathrm{r}^{2}=0,999$.

Similarly lycopene concentration was made using the method described by Fish [7] using the formula:

$$
\begin{aligned}
& \text { Lycopene }\left(\mathrm{mg} / \mathrm{Kg}_{\text {tissue }}\right) \text { : } \\
& \frac{A_{503_{n m}}{ }^{*} 536,9 g^{*} 1 L^{*} 10^{3} \mathrm{mg}^{*} 10 \mathrm{~mL}}{17,2^{*} 10^{4} / M^{*} \mathrm{~cm}^{*} \mathrm{~mol}^{*} 10^{3} \mathrm{~mL}^{*} 1 \mathrm{~g}^{*} \mathrm{Kg}_{\text {tissue }}}=\frac{A_{\text {s03n }}{ }^{*} 31,2}{g_{\text {tissue }}}
\end{aligned}
$$

Where $17.2 * 10^{4} / \mathrm{M} / \mathrm{cm}$ is the molar extinction coefficient for lycopene in hexane. We worked with a wavelength of $503 \mathrm{~nm}$ to minimize interference with other carotenoids; three fruit for each replicate (each treatment having 3 replicates) were taken at random from each treatment at the sampling date.

Statistical differences among data were analyzed using the statistical package Statgraphics. In order to establish statistically significant differences between the parameters analyzed and the control, the repeated-measures ANOVA with a significance level of 0.05 was performed (Statistics Treatment).

\section{Spectroscopic properties of the red compound}

Colorless needless; IR max (KBr) $\mathrm{cm}^{-1} 3440,2960,1450,1360,1060$, 1030, 970

${ }^{1} \mathrm{H}$ NMR $\left(300 \mathrm{MHz}, \mathrm{CDCl}_{3}\right) \delta 3.77$ (ddd, J=9.7, 3.9, $\left.1.5 \mathrm{~Hz}, 1 \mathrm{H}\right)$, 2.56 (ddt, J=13.4, 9.7, 3.3 Hz, 2H), $2.00(\mathrm{~m}, 1 \mathrm{H}), 1.90(\mathrm{~m}, 1 \mathrm{H}), 1.55(\mathrm{~m}$, $3 \mathrm{H}), 1.37$ (dd, J=3.7, 2.4 Hz, 1H), 1.35 (sbr, $4 \mathrm{H}), 1.32$ (sbr, $1 \mathrm{H}), 1.24$ (s, $3 \mathrm{H}), 1.14(\mathrm{~s}, 3 \mathrm{H})$.

${ }^{13} \mathrm{C} \mathrm{NMR} \mathrm{(75} \mathrm{MHz,} \mathrm{CDCl}_{3}$ ) and DEPT experiment: $\delta 73.59$ (s), 72.55 (s), 71.15 (d), 34.63, (t) 34.31 (d), 29.05 (q), 28.63 (q), 24.95 (q), $24.08(\mathrm{t}), 22.21(\mathrm{q})$.

MS, m/z: $170[\mathrm{M}+]$ (13), 137 (1), 126 (68), 111 (50), 109 (18), 108 (100), 93 (53), 83 (31), 71 (78), 69 (48), 58 (23), 55 (34)

\section{Results and Discussion}

\section{Comparison of chromatography profiles of tomato extracts}

Though assays lasted for 120 hours, it does not mean that 1,8-cineole was always present in the Petri dish since there was gas exchange with the atmosphere because the box was not hermetically sealed and also because of fruit breathing; not even after the first 24 hours 1,8-cineole was observed in the box.

Analysis by TLC and HPLC of 1,8-cineole treated and untreated tomato flesh did not show differences in their composition which is mainly starch and sugars. However, chromatography of exposed tomato exocarp extracts showed two important differences (Figure 1). The first relates to the changes in flavonoid composition, among them rutin, as well as a quercetin derivative -not fully identified, and lycopene. Through HPLC the presence of rutin and a quercetinderivative were observed in green untreated tomatoes, but lycopene was practically absent. In this way the initial concentration of rutin was $3.2 \mathrm{mg} / \mathrm{kg}$ exocarp and lycopene $0.10 \mathrm{mg} / \mathrm{kg}$. After 120 hours without 1,8-cineole, tomatoes were very ripe red and concentrations of rutin decreased until $1.97 \mathrm{mg} / \mathrm{kg}$ exocarp only a $64.4 \%$ of the initial amount. Meanwhile lycopene reveals a sharp increase in the concentration reaching a value of $2.12 \mathrm{mg} / \mathrm{kg}$ exocarp.

After 120 hours of the treatment 1,8-cineole fruit becoming green with reddish sites and the amount of lycopene was only $0.17 \mathrm{mg} / \mathrm{kg}$ and. Regarding rutin, a new concentration of $3.32 \mathrm{mg} / \mathrm{kg}$ exocarp was achieved, a similar value to those untreated fruits at time 0 hours. This mean that 1,8-cineole prevents the ripening course in the tomato fruit by a blocking of the lycopene biosynthesis while maintaining the levels of rutin, stopping the degradative process or keeping a continuous biosynthesis.

Although quercetin derivative was not determined, the correlation of the size of the peak in the HPLC was similar to the rutin and a similar process could be carried out in the fruit

Aside from the not too intense and homogeneous red of the inner part of the fruit and of the exocarp, other changes were observed. Unexposed fruits had peels more susceptible to deformities while the exocarp of exposed tomatoes was firmer and the pulp kept the initial hardness of the fruit.

According to thin layer chromatography, the second difference relates to the presence of $\mathrm{Rf}=0.41$ substance which is only found in treated tomatoes. This substance was further purified and its structure is described below (Supplementary NMR Spectra).

\section{Compound identification}

Mass spectra displayed a m/z peak 170.1, that us, 16 uma more than 1,8-cineole. The NMR spectra showed the presence of three methyl groups at $1.14,1.24$ and 1.35 . By a combination of ${ }^{13} \mathrm{C} \mathrm{NMR}$ spectra and JMOD and DEPT experiment, the presence of ten carbon atoms and two quaternary oxygenated atom carbons at 73.69 and 72.55 were detected, as well as an oxygenated methine at 71.15 , indicating an additional hydroxylation in the cineole moiety, a formula can be constructed with these data as $\mathrm{C}_{10} \mathrm{H}_{18} \mathrm{O}_{2}$. Thus, the structure 
of 2-hydroxy,1-8-cineole (Figure 2) was assigned on the basis of comparison of reported chemical shifts with authentic spectra of this compound, especially those reported for C6 [8].

Essential oils have been studied extensively as pesticides, but up to now, postharvest effects are not well founded, especially aspects concerning plant biochemistry, ripening processes and metabolic profiles. Results from this study provide evidence to establish that exposure of green tomatoes to 1,8-cineole vapors induce exocarp metabolic changes. In this case, the changes correspond to the lycopene biosynthesis. Similarly, the concentration of the two flavonoids, natural constituents of tomatoes [9], decreased during the ripening process of untreated tomatoes, but in treated tomatoes the initial levels of the unripe tomato is kept almost constant. It is worth noting that in this tomato variety flavonoid behavior is different to reports from other varieties, since increments of these substances during the ripening process have been found [10]; however, there is high flavonoid variability depending on the type of variety, crop conditions and storage $[11,12]$.

Up to now the exact correlation between flavonoid biosynthesis and tomato ripening is not known $[13,14]$, especially the biosynthesis of lycopene. In spite of the advances in metabolic engineering, a correlation of the specific interaction of the biosynthesis of these molecules has not been established. An approach to this issue could be the modulation of lycopene biosynthesis by the flavonoids since radiation affects the biosynthesis of lycopene [15], while the others are excellent absorbents of UV radiation. Nonetheless, the correlation between flavonoids and biosynthesis and action of ethylene in tomato is also unknown since tomato is a climacteric fruit [16].

1,8-cineole is a constituent molecule of tomato [17], but the isolated quantities let us assuming that its origin is exogenous. This is the first time that biotransformation of 1,8-cineole to 2-hydroxy1,8 -cineole in intact tomato cells is described; previous reports have been on fungi $[18,19]$, and rabbits [8]. It has been stated that essential oils aside from having antibiotic effects, they are also involved in fruit quality [20]; there have even been designed food packing with that type of antimicrobial agents [21].

Changes in the metabolism of cineole treated tomatoes can be used as a way to improve postharvest storage life, which is very short naturally, since it delays ripening and keeps fruit hardness. On the other hand, there is the possibility to externally manipulate the content of beneficial nutraceutics to human health in postharvest fruits since exposure to volatiles could increase those substances or eventually

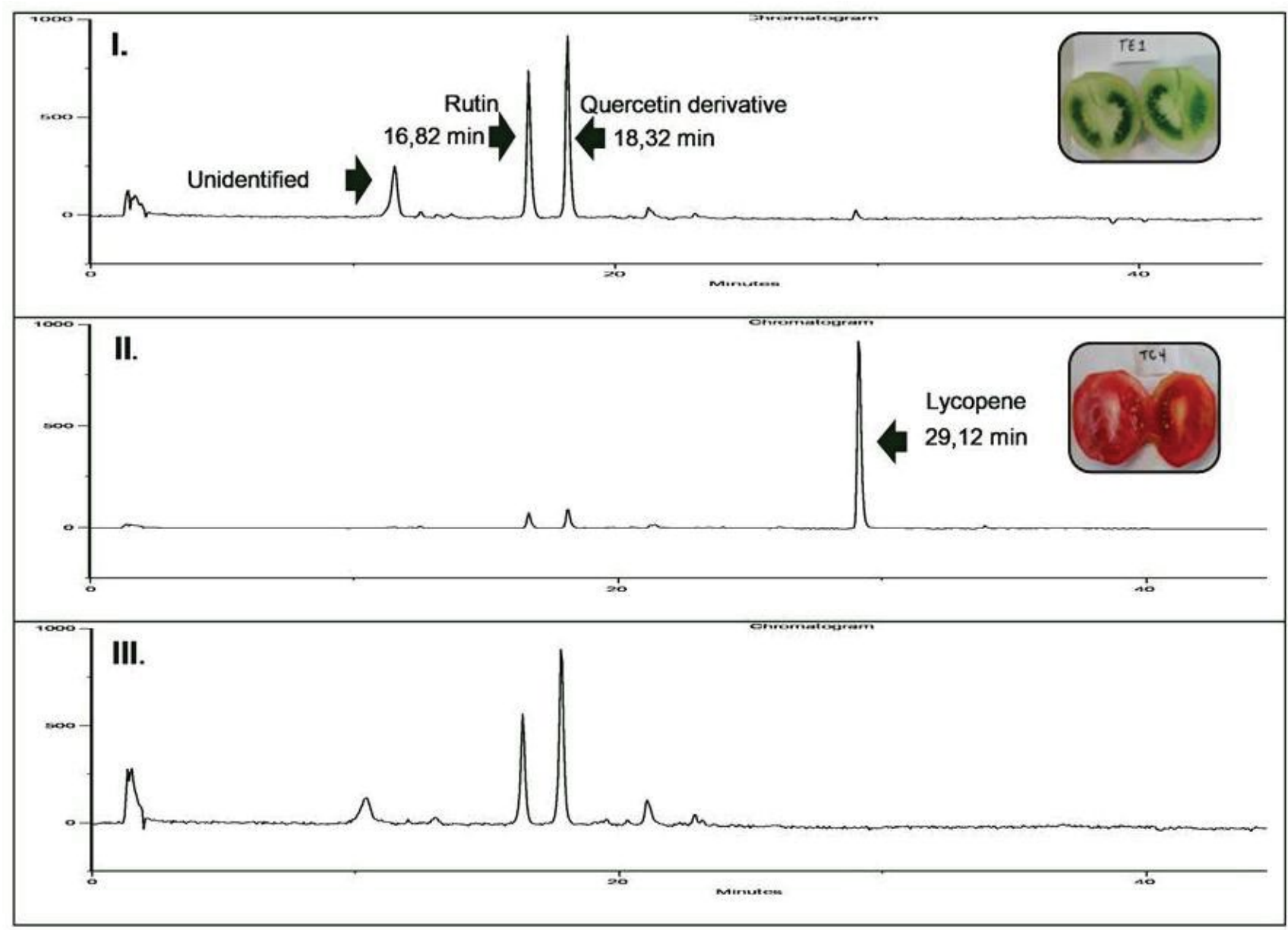

Figure 1: HPLC profiles of tomato extracts. (I) Green untreated tomatoes at time 0 of the assay, (II) at 120 hours of the assay and (III) tomatoes treated with 1,8 -cineole at 120 hours of the assay. 


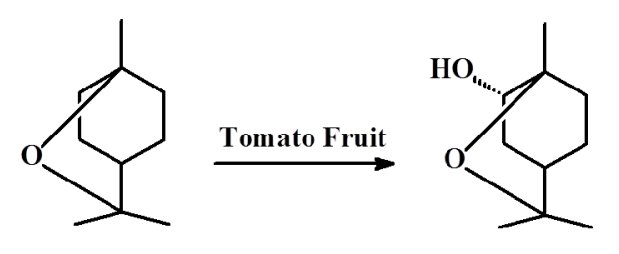

Figure 2: Structure of 1,8-cineole biotransformation product.

reduce their catabolism. Finally, exogenous application of natural substances to postharvest plants and fruits raises the possibility that they are absorbed and eventually biotransformed, modifying organoleptic properties, either because they are absorbed and incorporated to the nutritive mass, or else because as they are biotransformed and produce new aromas. It is even possible to obtain new molecules with new biological properties, among them antibiotic ones providing the plant with additional protection against pathogens.

In synthesis, we described here the capacity of 1,8-cineole to change the metabolism of some natural products in tomato fruit, in addition, plant cells were able to modify this essential oil to another natural product which as identified like 2-hydroxy-1,8-cineole.

\section{Acknowledgement}

Authors thank to Universidad de Antioquia (CODI) for funding the project IN635-CE.

\section{References}

1. Bebber DP, Gurr SJ (2015) Crop-destroying fungal and oomycete pathogens challenge food security. Fungal Genet Biol 74: 62-64.

2. CosicJ, Vrandecic K, JurkovicD (2014) The Effect of Essential Oils on the Development of Phytopathogenic Fungi, in Biological Controls for Preventing Food Deterioration: Strategies for Pre- and Postharvest Management. ( $\mathrm{N}$. Sharma, Ed.) Lucknow, India: John Wiley and Sons, Ltd, Chichester, UK.

3. Isman MB (2000) Plant essential oils for pest and disease management. Crop Prot 19: 603-608

4. Calo JR, Crandall PG, O'Bryan CA, Ricke SC (2015) Essential oils as antimicrobials in food systems - A review. Food Control 54: 111-119.

5. Prakash B, Kedia A, Mishra PK (2015) Plant essential oils as food preservatives to control moulds, mycotoxin contamination and oxidative deterioration of agrifood commodities - Potentials and challenges. Food Control 47: 381-391.
6. Batish DR, Singh HP, KohliR K, Kaur S (2008) Eucalyptus essential oil as a natural pesticide. Forest Ecol Manag 256: 2166-21747.

7. Fish WW, Perkins-Veazie P, Collins JK (2002) A quantitative assay for lycopene that utilizes reduced volumes of organic solvents. J Food Composition and Analysis 15: 309-317.

8. Miyazawa M, Kameoka H, Morinaga K, Negoro K, Mura N (1989) Hydroxycineole: Four new metabolites of, 8-cineole in rabbits. J Agric Food Chem 37: 222-226.

9. Vallverdú-Queralt $A$, Medina-Remón $A$, Martínez-Huélamo $M$, Jáuregui $O$, Andres-Lacueva C, et al. (2011) Phenolic profile and hydrophilic antioxidant capacity as chemotaxonomic markers of tomato varieties. J Agric Food Chem 59: 3994-4001.

10. Cano A, Acosta M, Arnao MB (2003) Hydrophilic and lipophilic antioxidant activity changes during on-vine ripening of tomatoes (Lycopersicon esculentum Mill.). Postharvest Biol Tec. 28: 59-65.

11. George B, Kaur C, Khurdiya DS, Kapoor HC (2004) Antioxidants in tomato (Lycopersium esculentum) as a function of genotype. Food Chem. 84: 45005110.

12. Gautier H, Diakou-Verdin V, Bénard C, Reich M, Buret M, et al. (2008) How does tomato quality (sugar, acid, and nutritional quality) vary with ripening stage, temperature, and irradiance? J Agric Food Chem 56: 1241-1250.

13. Tanaka Y, Ohmiya A (2008) Seeing is believing: Engineering anthocyanin and carotenoid biosynthetic pathways. Curr Opin Biotechnol 19: 190-197.

14. Liu L, Shao Z, Zhang M, Wang Q (2015) Regulation of carotenoid metabolism in tomato. Mol Plant 8: 28-39.

15. Severo J, Tiecher A, Pirrello J, Regad F, Latché A, et al. (2015) UV-C radiation modifies the ripening and accumulation of ethylene response factor (ERF) transcripts in tomato fruit. Postharvest Biol Tec 102: 9-16.

16. Klee HJ, Giovannoni JJ (2011) Genetics and control of tomato fruit ripening and quality attributes. Annu Rev Genet 45: 41-59.

17. Vallverdú-Queralt $A$, Bendini A, Tesini F, Valli $E$, Lamuela-Raventos RM, et al (2013) Chemical and sensory analysis of commercial tomato juices present on the Italian and Spanish markets. J Agric Food Chem 61: 1044-1050.

18. Bhatti HN, Khan SS, Khan A, Rani M, Ahmad VU, et al. (2014) Biotransformation of monoterpenoids and their antimicrobial activities. Phytomedicine 21: 15971626.

19. Bicas JL, Dionísio AP, Pastore GM (2009) Bio-oxidation of terpenes: An approach for the flavor industry. Chem Rev 109: 4518-4531.

20. Sivakumar D, Baños SB (2014) A review on the use of essential oils for postharvest decay control and maintenance of fruit quality during storage. Crop Prot. 64: 27-37.

21. Irkin R, Esmer OK (2015) Novel food packaging systems with natural antimicrobial agents. J Food Sci Technol 52: 6095-6111. 